\title{
MODELING THE ANNUAL THERMAL REGIME OF LAKE OHRID, YUGOSLAVIA, USING DAILY WEATHER DATA
}

\author{
SAMUEL I. OUTCALT \\ Department of Geography, University of Michigan, Ann Arbor, MI 48109 (U.S.A.) \\ HAROLD L. ALLEN \\ Department of Biology, University of Toledo, Toledo, OH 43606 (U.S.A.) \\ (Accepted for publication 8 November 1981)
}

\begin{abstract}
Outcalt, S.I. and Allen, H.L., 1982. Modeling the annual thermal regime of Lake Ohrid, Yugoslavia, using daily weather data. Ecol. Modelling, 15: 165-184.

The time-dependent characteristics of the five weather variables which control the annual thermal response of Lake Ohrid are analyzed in detail. These are daily values for solar radiation, air temperature, humidity, wind speed and cloud cover. A simple numerical model of the lake's thermal response, forced by thermally driven density mixing, is developed and tested using observed thermal profiles for verification. The numerical model successfully reproduces the major features of the lake's thermal regime over a 6 y period from 1972 to 1977 , the average root mean square value for the simulated profiles being $1.2^{\circ} \mathrm{C}$ with extremes of 2.2 and $0.3^{\circ} \mathrm{C}$ and a standard deviation of $0.4^{\circ} \mathrm{C}$.
\end{abstract}

\section{INTRODUCTION}

Lake Ohrid, astride the Yugoslavian-Albanian frontier, is an ancient lake occupying a Pliocene graben (Stanković, 1960; see also Allen and Ocevski, 1976). The lake has a surface area of $348 \mathrm{~km}^{2}$, a mean depth of $145 \mathrm{~m}$ and a maximum depth of $298 \mathrm{~m}$. The water surface elevation is $695 \mathrm{~m}$. The lake is bounded on the east and west by abrupt ridge systems attaining elevations between 1.5 and $2.0 \mathrm{~km}$ (Fig. 1). The terrestrial drainage basin is steep and small, having an area approximately equal to the surface area of the lake. Inflow to the lake is dominated by snowmelt runoff and is augmented to an unknown but significant degree by groundwater flow in calcareous strata.

For over a century, the lake and its endemic and relict biota have been studied by scientists at the Hydrobiological Institute in Ohrid (Stankovic, 


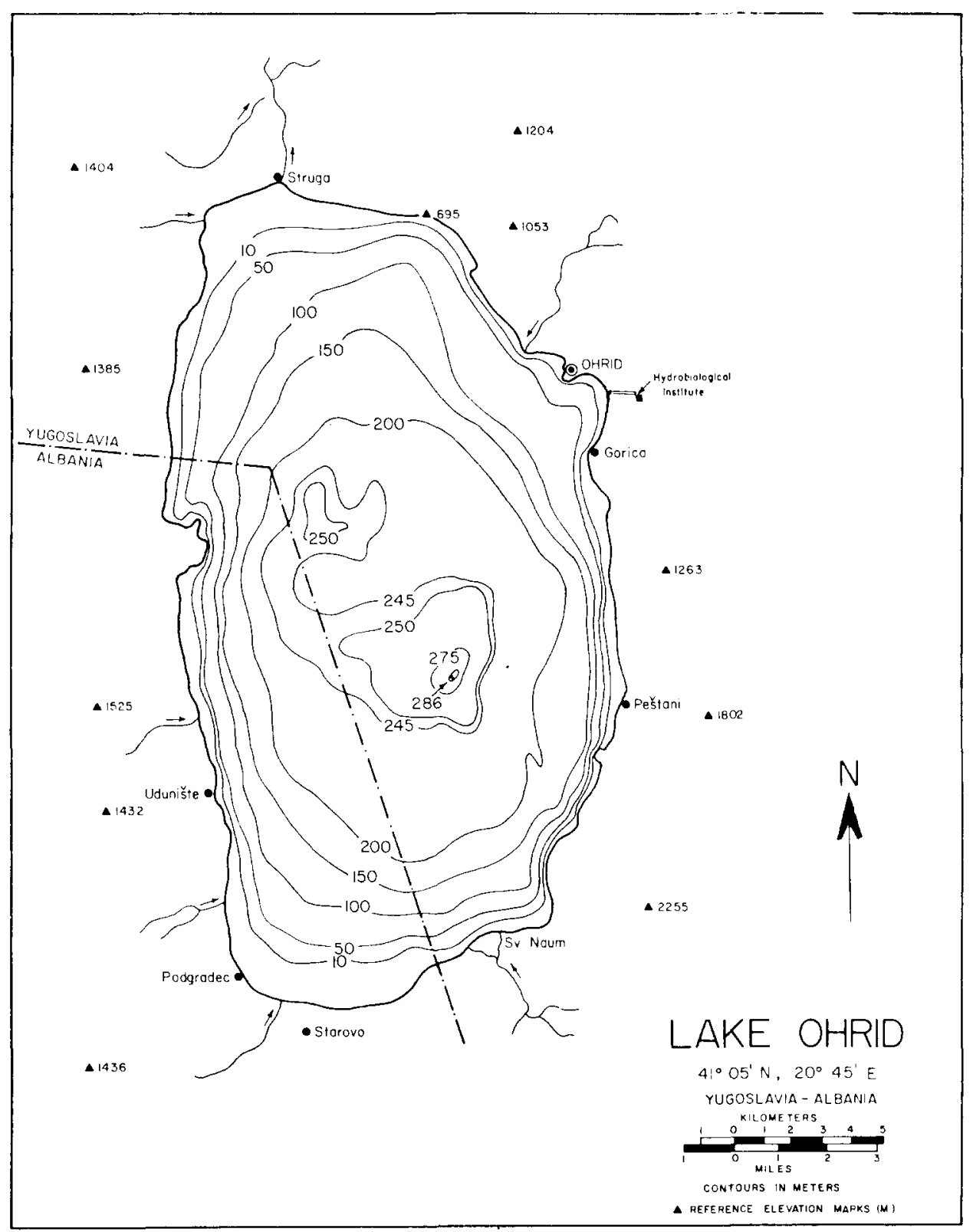

Fig. 1. Morphometric map of Lake Ohrid, Macedonia, Yugoslavia.

1960). Most of this work was devoted to biological topics. However, monthly water temperature profiles were measured for many years (Stankovic and Hadžišče, 1953). During the past decade the Smithsonian Institution of 
Washington, DC, has developed a cooperative research program with the Hydrobiological Institute. This paper describes the nature of daily weather variation and the performance of an improved version of the lake thermal model originally described by Outcalt and Allen (1981).

\section{WEATHER DATA}

Dr. Jordanka Hadžišče obtained records of the mean daily air temperature, humidity, wind velocity and cloud cover at Ohrid and the solar radiation record from Bitola, $60 \mathrm{~km}$ to the east. These data were collected by the Hydro-Meteorological Institute of Skopje. In contrast to the earlier paper by Outcalt and Allen (1981) which used an empirical estimate of solar radiation at Ohrid, the Bitola solar radiation time-series is employed here with the assumption that it is representative of conditions at Ohrid. The weather data set consists of daily observations of the meteorological variables for a 6 y period: 1972-1977. These raw time-series appear in Fig. 2 in computer plots directly from the weather data file. Graphs of monthly means and record extremes are presented in Fig. 3. The nature of the time-dependent behavior of this data set will now be discussed in detail.

Solar radiation has an extremely strong periodic component as does air temperature. Wind velocity has no significant periodic component (less than $5 \%$ total variance), while the periodic components of cloud cover and relative humidity are significant but weak. The periodic components of all variables except wind speed closely approximate the monthly mean values. Wind speed has no significant periodic component, and reveals very little annual variation with extreme wind maxima occurring in late autumn and spring.

Histograms of the raw time-series are presented in Fig. 4. Only relative humidity, which is physically limited, approaches a normal distribution. Solar radiation is flat but demonstrates periodic control. The temperature histogram is bimodal, influenced by the mean temperatures of summer and winter air masses $\left(6\right.$ and $\left.19^{\circ} \mathrm{C}\right)$. Note that $6^{\circ} \mathrm{C}$ is the approximate temperature of the hypolimnion. The wind velocity histogram is strongly skewed with a well-developed maximum-frequency at $150 \mathrm{~cm} \mathrm{~s}^{-1}$. Ohrid is an extremely calm location. The record mean velocity is below $10 \mathrm{~m} \mathrm{~s}^{-1}$. The cloud cover histogram illustrates the frequent occurrence of nearly clear and overcast days.

The autocorrelation and spectral density functions of the residual timeseries developed by removal of trend and periodic components are presented in Fig. 5. Air temperature, humidity and cloud cover exhibit much stronger autocorrelation than wind and solar radiation. High autocorrelation is apparently associated with air mass change and the scale/velocity of atmospheric disturbances. The autocorrelation functions exhibit no evidence of 

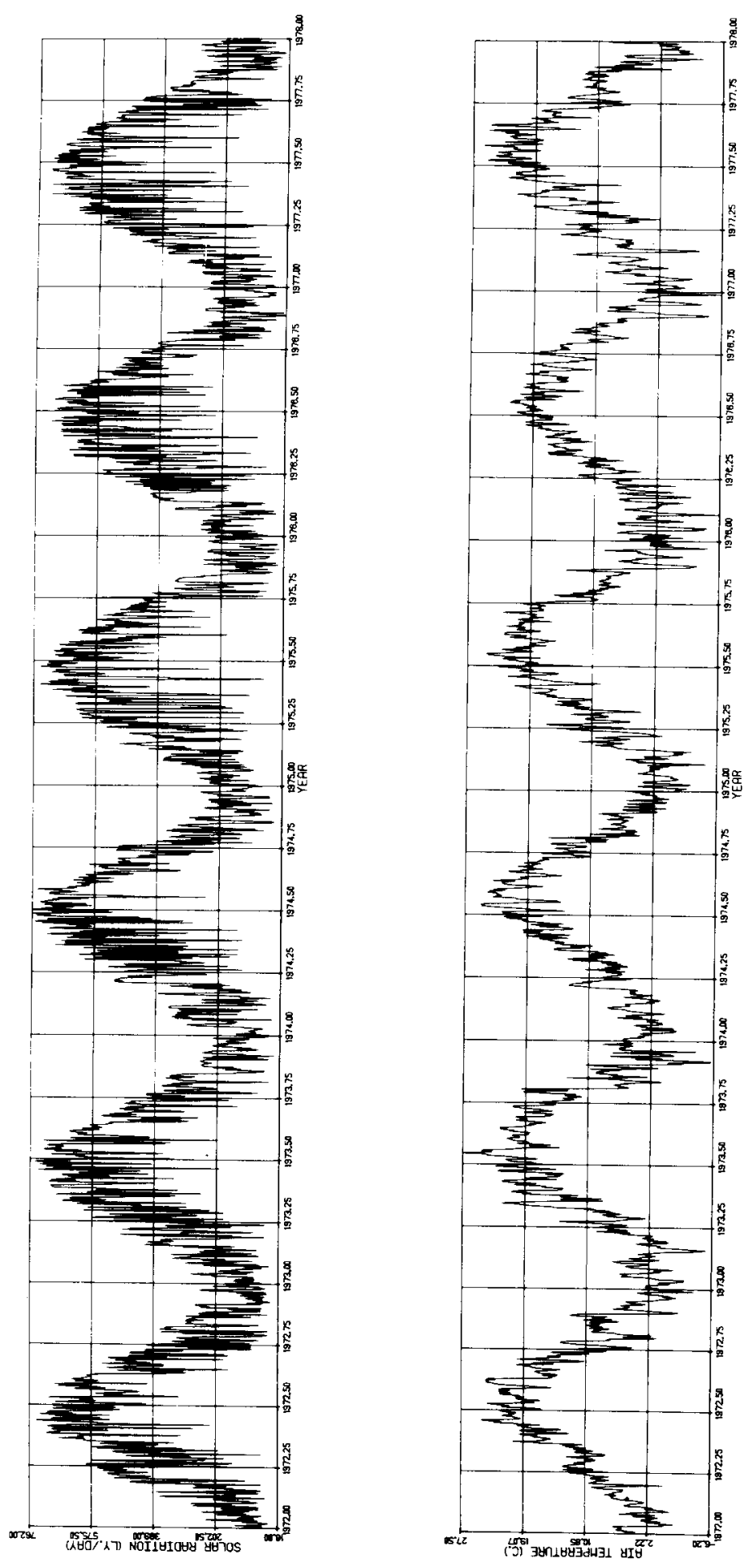

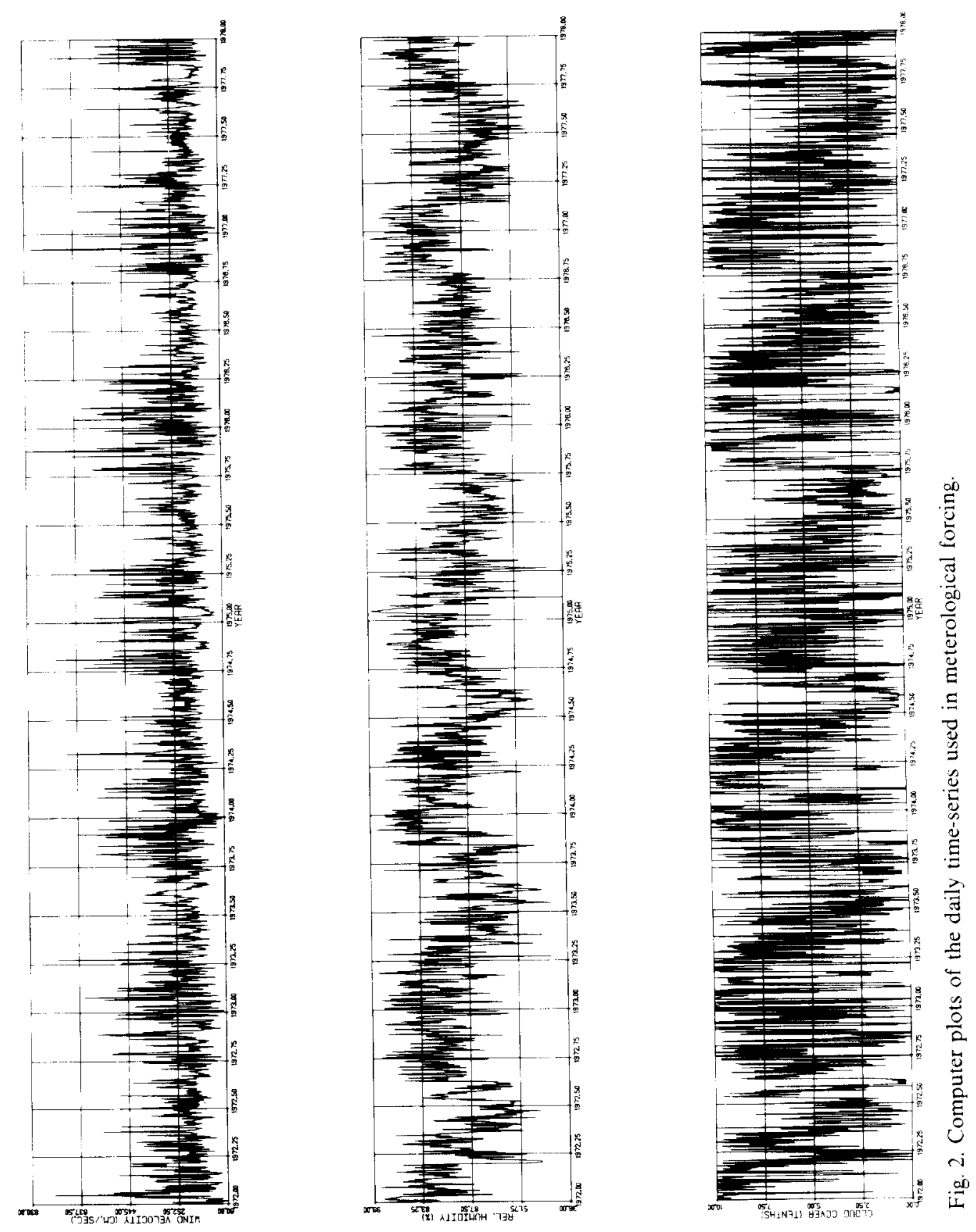


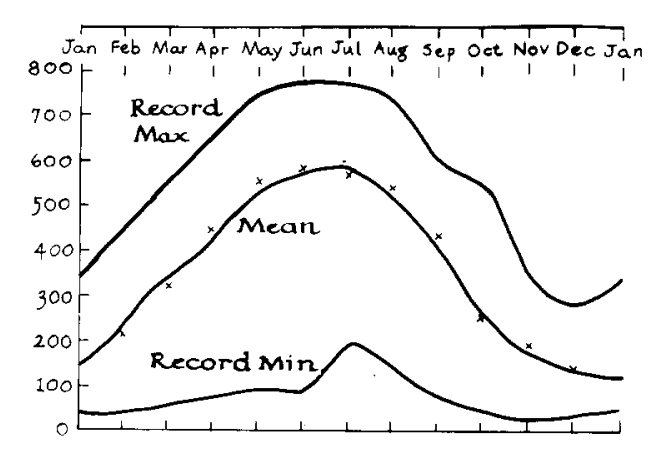

SOLAR RADIATION (Ly/day)

$\times$ Periodic Component

( $66 \%$ of total variance)

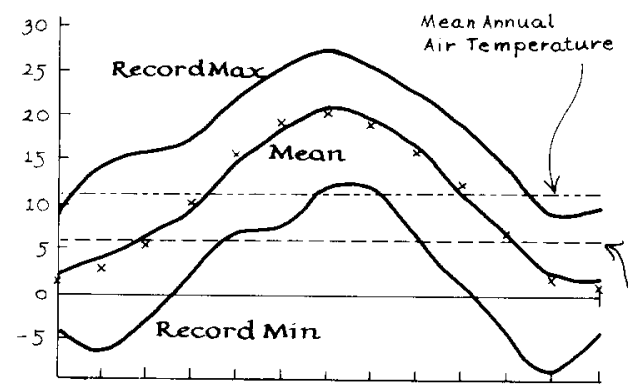

AIR TEMPERATURE $\left({ }^{\circ} \mathrm{C}\right)$

$\times$ Periodic Component

( $82 \%$ of total varíance)

Temperature of

Hypolimnion

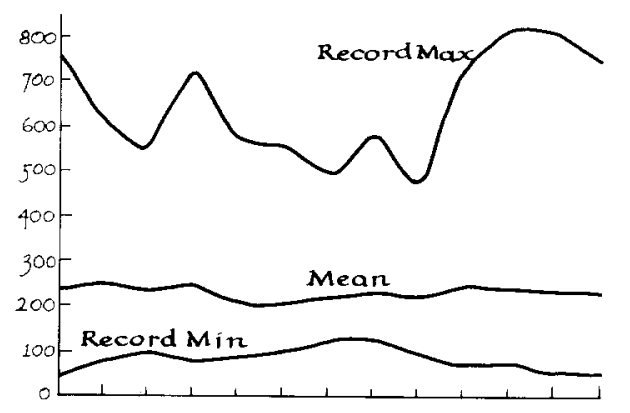

WINDVELOCITY $(\mathrm{cm} / \mathrm{sec})$

no periodic component

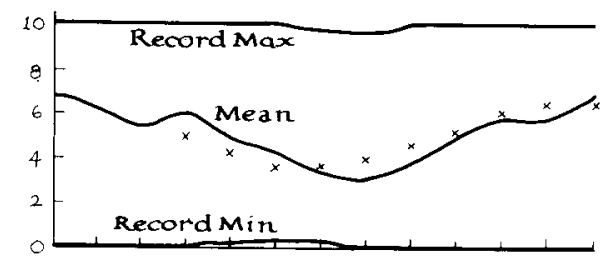

ClOUD COVER (tenths)

$\times$ Períodic Component

(10\% of the variance)

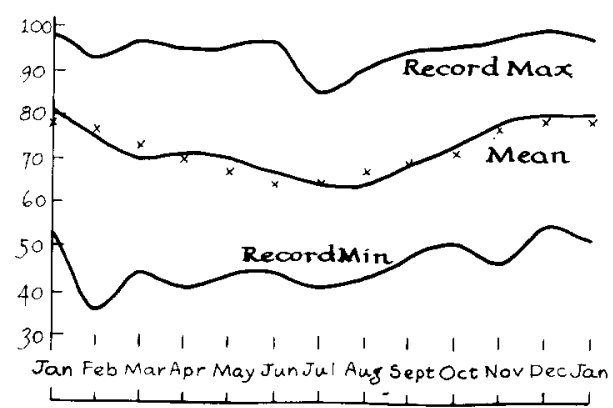

RELATIVE HUMIDITY (\%)

$x$ Periodic Component

(22\% of total variance)

Fig. 3. The annual weather regime of Ohrid during the observation period 1972-1977. 

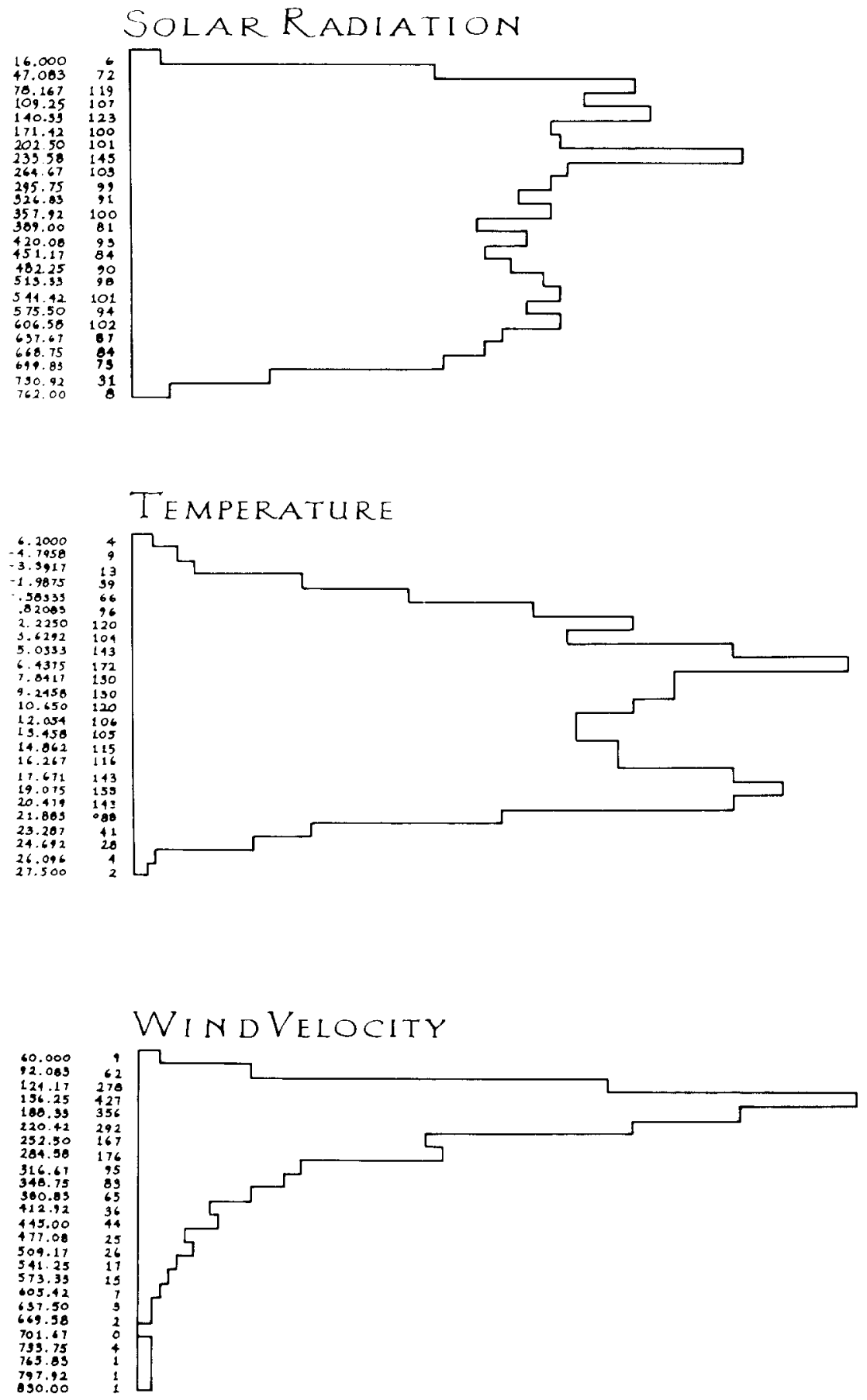

Fig. 4. Histograms of weather variables. 

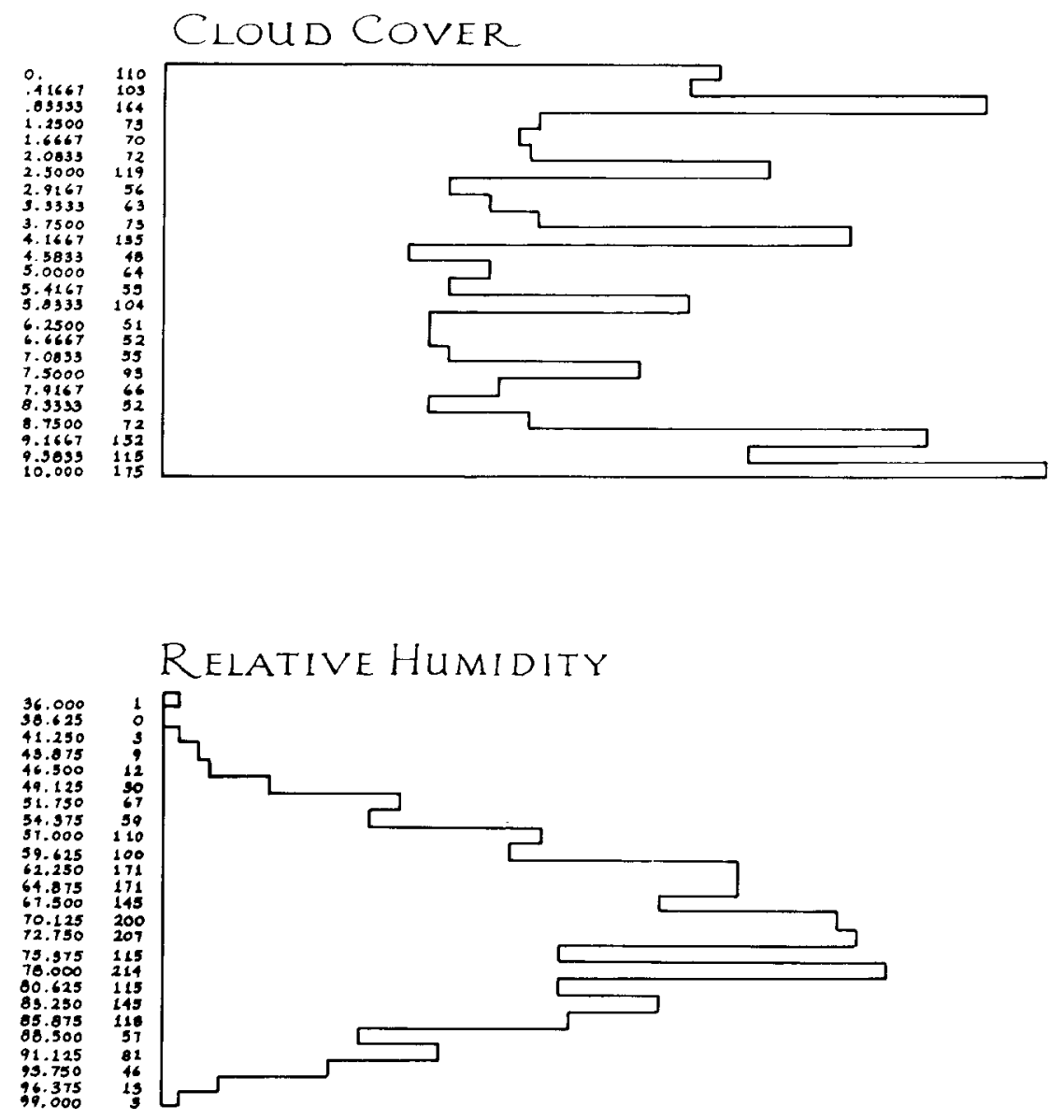

periodic control at frequencies lower than the record length as the integrals of all the autocorrelation functions approach a constant value with increasing lag. The weak spike in the solar radiation spectral density function at the lag of $27 \mathrm{~d}$ may be related to the influence of sunspots modulated by the angular velocity of the sun, while no physical significance is attached to the strong spike in the spectral density function for wind velocity in the same region. Numerous spectral spikes in the temperature, humidity and cloud graphs may be the product of the quasi-periodic nature of air mass change and weather scale which produced high frequency autocorrelation in these variables. The spectra for wind appears to be the product of a random or noisy process at the data frequency, while solar radiation appears less noisy.

In summary, air temperature, humidity and cloud cover exhibit strongly time-correlated or Markovian behavior, while wind appears to approximate random behavior. In this continuum, solar radiation is intermediate. 

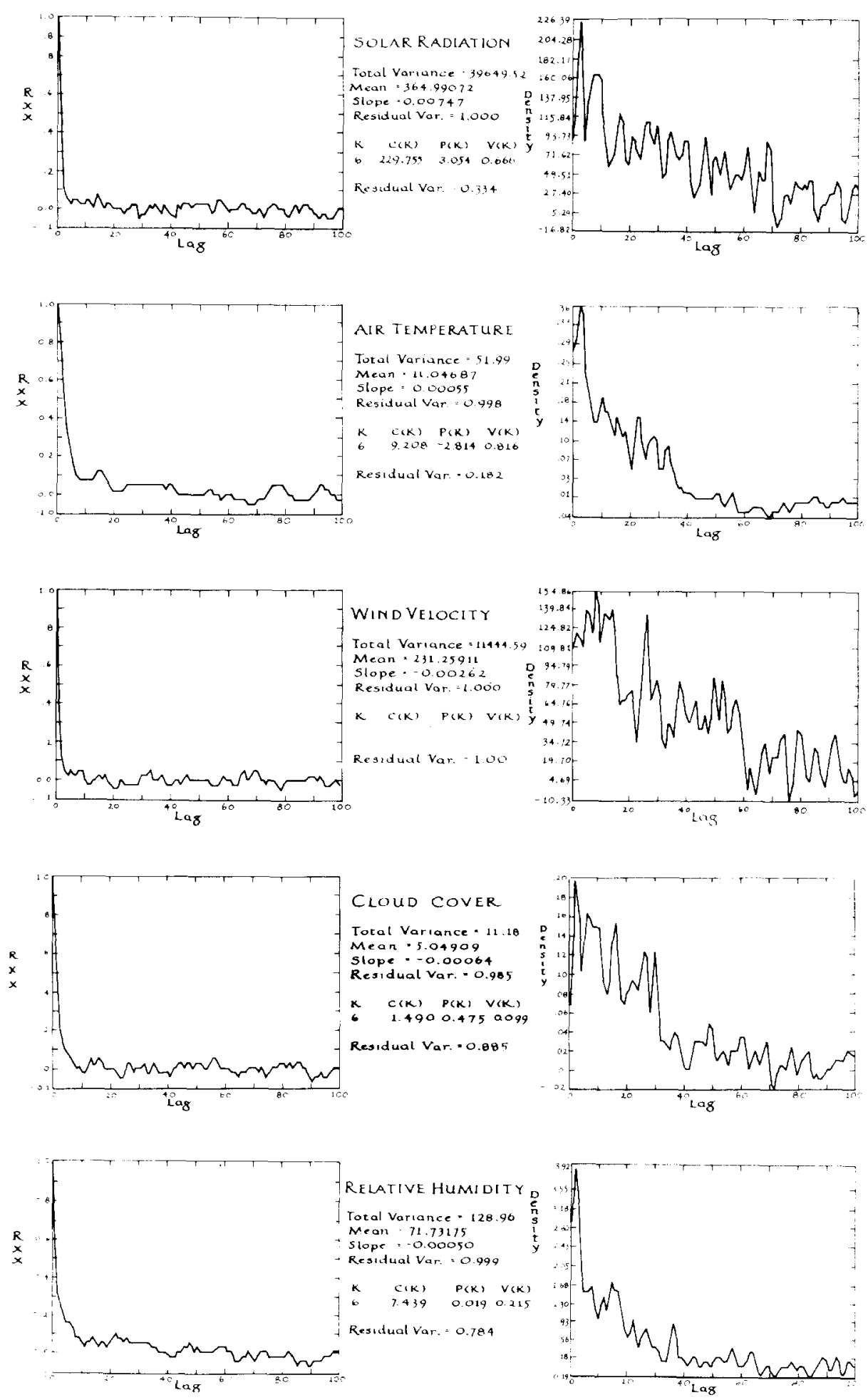

Fig. 5. Autocorrelation of spectral density functions of the forcing time-series after removal of trends and low-frequency (annual) periodicity. Key: K, harmonic number; $\mathrm{C}(\mathrm{K})$, harmonic amplitude: $\mathrm{P}(\mathrm{K})$, harmonic lag in radians; $\mathrm{V}(\mathrm{K})$, fraction of variance in harmonic. 


\section{LAKE DATA}

Dr. Boris Ocevski of the Hydrobiological Institute generously made available a set of quasi-monthly temperature profile data taken at depths of $0,5,10,15,20,25,30,40,50,100,150,200$ and $240 \mathrm{~m}$ during the period from 23 October 1972 to 6 December 1977. These data were taken near the geographical center of the lake where the depth is $240 \mathrm{~m}$ and are used in the later validation of the thermal model.

\section{THE THERMAL REGIME OF LAKE OHRID}

Ohrid is classified as an oligiomictic lake. The temperature of the hypolimnion through the years of observation varied only slightly from $6^{\circ} \mathrm{C}$. These observations of lakewater temperature date back to 1929. The lake surface layers never cool below the temperature of maximum density $\left(3.94^{\circ} \mathrm{C}\right)$ for a sufficient period of time to produce mixing to any significant depth. However, discontinuous thin ice cover does form during brief winter subfreezing periods. The thermocline is usually well developed during the period of summer warming. During this period the near surface layers (above $50 \mathrm{~m}$ ) may be nearly isothermal or show a strong decrease of temperature with depth. The summer near surface isothermal conditions must be the product of a recent cold period initiating density-driven down-mixing or the effects of increased wind velocity. In autumn the surface layers cool, creating a nearly isothermal epilimnion above a distinct thermocline which only broke one year in seven (Hadžišče, 1966). The circulation in rare years occurs when the epilimnetic water cools to a density greater than that of the hypolimnion. These events are usually the result of extreme cold spells during the winter months. In the period from 1972 to 1977 the lowest recorded mean daily air temperature at Ohrid was $-6.2^{\circ} \mathrm{C}$, while the mean annual temperature for the same period was $11^{\circ} \mathrm{C}$.

\section{THE STRUCTURE OF A LAKE THERMAL MODEL}

In attempting to construct a simple model of the response of a lake thermal structure to meteorological conditions there are two major steps. First, it is necessary to calculate the surface or air-water interface temperature and, second, the influence of that surface temperature change on the thermal profile at depth. These topics will now be discussed in turn.

The calculation of mean daily lake surface temperatures from meteorological data

The data necessary for this calculation are grouped in several broad categories. First, it is necessary to estimate several near surface properties. 
These properties are the 'effective thermal conductivity' of the water in the epilimnion, the albedo of the water surface and the extinction coefficient of the lake water. A previous study of the penetration rate of summer warming yielded a value for the 'effective thermal diffusivity' of approximately $0.14 \mathrm{~cm}^{2} \mathrm{~s}^{-1}$ for the epilimnion of Lake Ohrid using the formula of Terzaghi (1952). This value was in the range of values calculated for the epilimnion of Lake Tiberias by Lerman and Stiller (1969). The mean daily albedo was set at 0.07 or 0.60 depending on air temperature. An extinction coefficient was estimated at $0.0018 \mathrm{~cm}^{-1}$ as a representative value for a clear lake.

The notation used in the following discussion of the surface energy budget is listed in the Appendix. The energy conservation expression for the air-water interface can be written as follows.

$R_{n 1}+H+E+S=0.0$

Using $T$ as the air-water interface temperature, the components of the previous equation are in increased detail.

$$
\begin{array}{ll}
R_{n 1}=N(n)\left(B B\left(T_{\text {sky }}\right)-B B(T)\right) & \text { (net thermal radiation) } \\
H=B X(U)\left(T_{\mathrm{a}}-T\right) & \text { (sensible heat flux) } \\
E=X(U)\left(E\left(T_{\mathrm{a}}, R H\right)-E(T, 100)\right) & \text { (evaporative heat flux) } \\
S=(K / \mathrm{d} Z)\left(T_{z}-T\right) & \text { (substrate heat flux) }
\end{array}
$$

Note that solar radiation does not appear in the surface energy conservation expression as it penetrates the surface and warms the water at depth. The calculation of solar heating will appear later. The substrate heat flux is calculated using the temperature $T_{z}$ at depth $\mathrm{d} Z$. The only unknown in the equation of energy conservation is the surface temperature $(T)$. The energy conservation equation may now be written in a form in which all of the components are functions of an estimated surface temperature $\left(T_{i}\right)$ yielding a non-zero sum (error, $)$.

$R_{n 1}\left(T_{i}\right)+H\left(T_{i}\right)+E\left(T_{i}\right)+S\left(T_{i}\right)=$ error $_{i}$

Note that in a correctly specified system as $T_{i}$ approaches the actual surface temperature $(T)$ the error ${ }_{i}$ will approach zero. The Newton-Raphson method is employed to optimize successive estimates of $T_{i}$. Convergence to within $0.01 \mathrm{ly}^{-1}$ is usually achieved within ten iterations (Outcalt et al.. 1975).

\section{The simulation of lake thermal profiles}

The next step in the problem is to calculate the thermal regime of the lake as forced by the changing surface temperature history. This is accomplished by solving a finite difference approximation of eq. 7 and then checking the 
result at each level for density down-mixing.

$$
\frac{\delta T}{\delta t}=\left\{\frac{1}{C} \frac{\delta[K(\delta T / \delta Z)]}{\delta Z}+\frac{\delta Q}{\delta Z}\right\} \quad \begin{aligned}
& |\delta T / \delta Z|>0.1^{\circ} \mathrm{C} \mathrm{m}^{-1}, K=0.14 \\
& |\delta T / \delta Z| \leqslant 0.1^{\circ} \mathrm{C} \mathrm{m}^{-1}, K=1.43 \times 10^{-3}
\end{aligned}
$$

where $t$ is the time and $Z$ is the depth. The second term of the right-hand side of eq. 7 has a convenient analytical solution if the extinction coefficient is not a function of depth (Maykut and Untersteiner, 1971).

$$
\left(\frac{\delta T}{\delta t}\right)_{Q}=\frac{(1-a) Q_{\mathrm{g}} m}{C} \exp [-m Z]
$$

The numerical algorithms employed to solve eq. 7 are discussed by Carnahan et al. (1969) in considerable detail. Unfortunately, the solution is modulated by both the algorithm and the space-time geometry selected for the calculations (Outcalt, 1979). At each level, where water temperature is calculated, it is possible to calculate a water density as a function of temperature and depth. It is also possible to calculate a mean density $\bar{\rho}$ from the surface to any subsurface level $Z_{*}$.

$\bar{\rho}=\frac{1}{Z_{*}} \int_{0}^{z_{*}} \rho(T, Z) \mathrm{d} Z$

If at any depth the density is greater than the layer beneath that level the integration must continue including that level until the condition is removed. In a similar manner it is also possible to calculate:

$\bar{T}=\frac{1}{Z_{*}} \int_{0}^{z_{*}} T(Z) \mathrm{d} Z$

When a level is reached at which the density of the water in the next level downward is greater than the mean density, the process stops and at all levels between the surface and that level the mean temperature replaces the initial temperature. This process thus simulates gravity-density mixing.

$T(Z) \leftarrow \bar{T}, \quad Z=0, \ldots, Z_{*}$

Currently, the simulator imposes a synthetic diurnal thermal regime on the temperature-density algorithm discussed above. This procedure is applied to cover the extremes of a diurnal cycle which is made a function of cloud cover and uses the solution for mean daily surface temperature $\left(T_{0}\right)$ as the mean value. The equation for the synthetic cycle appears below.

$T_{j}=T_{0}+T \sin [j(\pi / 2)], \quad j=1,2,3,4$

where: $T=2[(10-\mathrm{n}) / 10]$. This equation is used to force the series of 
operations described by eqs. $7-11$ by generating a surface temperature 7 . Runoff from the surrounding terrain must have some impact on the lake temperature as this water arrives from the land and mixes with the surface waters. In a similar mode precipitation falling on the surface must influence the air-water interface temperature. Therefore the mean daily surface temperature used in eq. 12 is a weighted-value of the temperature resulting from the energy budget calculation and the air temperature.

$T_{0}=0.2 T_{\mathrm{a}}+0.8 T$

Note that in eq. 7 the thermal conductivity is a function of the temperature gradient. The values are representative of still water and earlier analyses of the rate of penetration of the thermocline.

In summary, the calculations proceed in the following manner: a surface temperature is calculated from the energy conservation equation. This value. combined with air temperature to synthesize surface runoff effects. is used to simulate a diurnal surface thermal regime which forces the temperature density-mixing algorithm (eqs. 7-11) four times during a diurnal cycle. It should be stressed that the temperature-density-mixing algorithm is a departure from standard practice in limnology. The most frequently employed strategies are to use an analytical or numerical solution to the temperature diffusion equation. In order of sophistication these tactics involve the estimate of 'effective thermal conductivity' as a function of the depth. temperature and temperature gradient or Richardson Number (an index of stability). These models may become extremely complex and contain varied measures of theory and empirical parameterization. The topic has been excellently reviewed by Walters (1977). Here the process has been quantized' by the addition of the density-mixing cycle. A node spacing of $0.5 \mathrm{~m}$ and a time-step of $6 \mathrm{~h}$ is currently employed. This space-time calculation mesh requires the application of an implicit numerical solution. The standard tridiagonal matrix solution is employed. The output of a numerical model is the product of both the model physics and the numerical algorithm selected for the solution of the resulting equations.

\section{LIMITATIONS OF THE MODEL STRUCTURE}

The model discussed here is not really a model of Lake Ohrid. It is a one-dimensional model of a semi-infinite horizontally homogeneous lake which is $240 \mathrm{~m}$ deep. There is no wind mixing of the surface waters as all mixing is restricted to density forced mixing as described by the self-modeling temperature--density algorithm. The inclusion of runoff-precipitation effects in eq. 13 is an expedient approach lacking in sophistication and justification in detail. The use of $U, T_{\mathrm{a}}$ and $R H$, measured in Ohrid on a low 
ridge overlooking the lake, in the turbulent flux equations ( 3 and 4) carries with it the assumption that these values are representative of the limnological site near the center of the lake. The assumptions surrounding the effective thermal conductivity have been discussed previously. The thermal structure of the upper layers of the epilimnion is extremely sensitive to the value of the extinction coefficient, and the assumption that the value is independent of depth and time. The use of a composite extinction coefficient which includes both scattering and absorption effects averaged over the solar spectrum is expedient.

\section{MODEL RESPONSE TO METEOROLOGICAL FORCING}

The simulation began on 1 January 1972 with all computation levels assigned a temperature of $6.3^{\circ} \mathrm{C}$ corrected for pressure at depth. The simulated profiles were never corrected during the simulation run. Additional nodes for computation were added to simulate heat flow to and from the bottom sediments. Seventy-eight observed thermal profiles were available for comparison with simulated profile data. From these profiles, one from March, June, September and December was selected in each year from 1973 to 1977 . The 1972 profiles were not used for comparison as model response was conditioned in that year. The root mean square values resulting from the comparison of simulated and observed temperatures at the 13 observation depths are presented in Table I. Isotherms of the observed and simulated thermal regimes are presented in Fig.6, and typical seasonal profiles are presented in Fig. 7 for the years 1973, 1975 and 1977.

It is evident from Fig. 5 that the simulated thermal regime is smoother than the observed isothermal surface. However, the simulated surface shows considerable interannual variation. At least a part of the variation between the observed and simulated isothermal surfaces must be due to meteorological variability during the days of observation at frequencies much higher than the modeling frequency which is $6 \mathrm{~h}$.

The profiles presented in Fig. 6 are typical of the entire set of 78 comparisons. These plots show that the simulated hypolimnion was several tenths of a degree Celsius colder than those observed. Further, during the development of the epilimnion $(74 / 6 / 27,74 / 9 / 19,77 / 6 / 8,77 / 9 / 20)$ there was frequently a rather large deviation from the observed structure of the epilimnion and thermocline. An underestimate of both the depth of the thermocline and the warmth of the epilimnion was common in most profiles covering summer warming. These errors may be reduced by the addition of a seasonally variable extinction coefficient, a more realistic model of the effect of terrestrial inflow when the lake waters are strongly stratified, and a depth-dependent 'effective thermal diffusivity' treated as a function of wind 
TABLE I

Root mean square (RMS) values for simulated profiles

\begin{tabular}{lrll}
\hline $\begin{array}{l}\text { Observation date } \\
\text { (year/month/day) }\end{array}$ & $\begin{array}{l}\text { RMS } \\
\left({ }^{\circ} \mathrm{C}\right)\end{array}$ \\
\hline 73 & 3 & 21 & 0.3 \\
73 & 6 & 28 & 0.9 \\
73 & 9 & 21 & 1.3 \\
73 & 12 & 25 & 1.5 \\
74 & 3 & 13 & 0.7 \\
74 & 6 & 27 & 1.4 \\
74 & 9 & 11 & 1.2 \\
74 & 12 & 5 & 0.9 \\
75 & 3 & 28 & 0.6 \\
75 & 6 & 26 & 1.3 \\
75 & 9 & 1 & 1.7 \\
75 & 12 & 11 & 2.2 \\
76 & 6 & 16 & 1.3 \\
76 & 9 & 16 & 1.3 \\
76 & 12 & 22 & 1.0 \\
77 & 3 & 2 & 1.1 \\
77 & 6 & 8 & 1.1 \\
77 & 9 & 7 & 0.9 \\
77 & 12 & 6 & 0.9
\end{tabular}

Mean RMS, $1.2^{\circ} \mathrm{C}$; Standard deviation RMS, $\pm 0.4^{\circ} \mathrm{C}$.

velocity. However, all these improvements await experimental data. During the autumn-winter cooling $(74 / 3 / 13,74 / 12 / 5,77 / 3 / 22,77 / 12 / 6)$ the profile curvatures are similar, but the simulated epilimnion is warmer. These deviations from reality may be improved by the modifications discussed above.

The remarkable attribute of the simulator is its ability to mimic the thermal regime as well as it does considering the limitations described in previous sections of this paper. Further, the work indicates that the thermal regime of Lake Ohrid may be the product of a thermal-density-mixing mechanism similar to the 'quantized model' proposed in this paper. The Ohrid meteorological station reported a 6-y maximum mean daily wind velocity of $8.3 \mathrm{~m} \mathrm{~s}^{-1}$, while the mean was $2.3 \mathrm{~m} \mathrm{~s}^{-1}$ with a standard deviation of $1.0 \mathrm{~m} \mathrm{~s}^{-1}$. Thus, Lake Ohrid does not appear to be subjected to significantly strong wind activity and, hence, wind mixing may not be extremely important in establishing the annual thermal regime. 

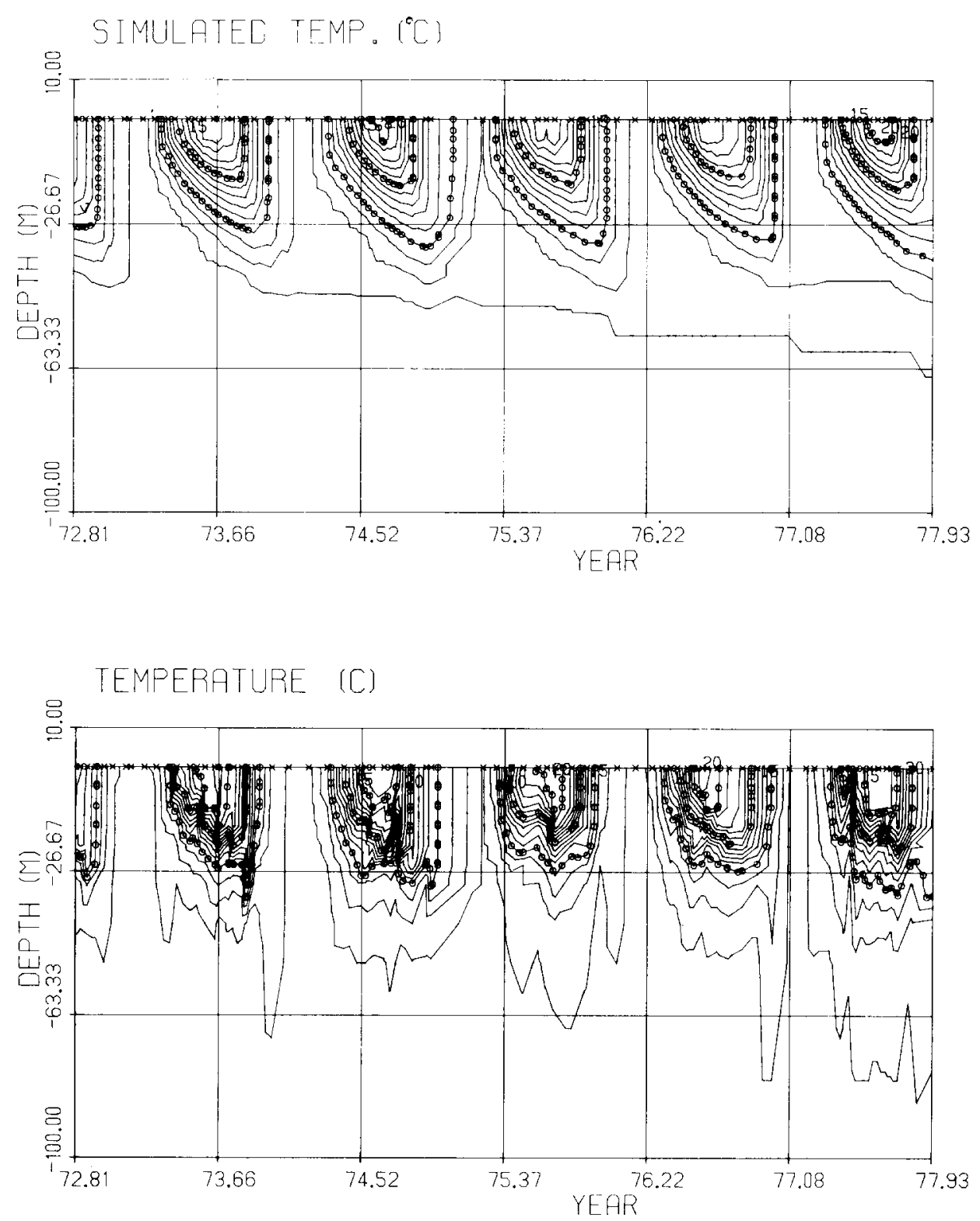

Fig. 6. Simulated (upper) and observed (lower) isotherms for time period October 1972 to October 1977; interval: $1^{\circ} \mathrm{C}$. Index isotherms are at $5^{\circ} \mathrm{C}$. In both diagrams the deepest isotherm is $7^{\circ} \mathrm{C}$.

It is anticipated that the modeling methodology described in this paper will be applied to other deep lake systems in order to validate and refine its general usefulness in predicting thermal profiles. 

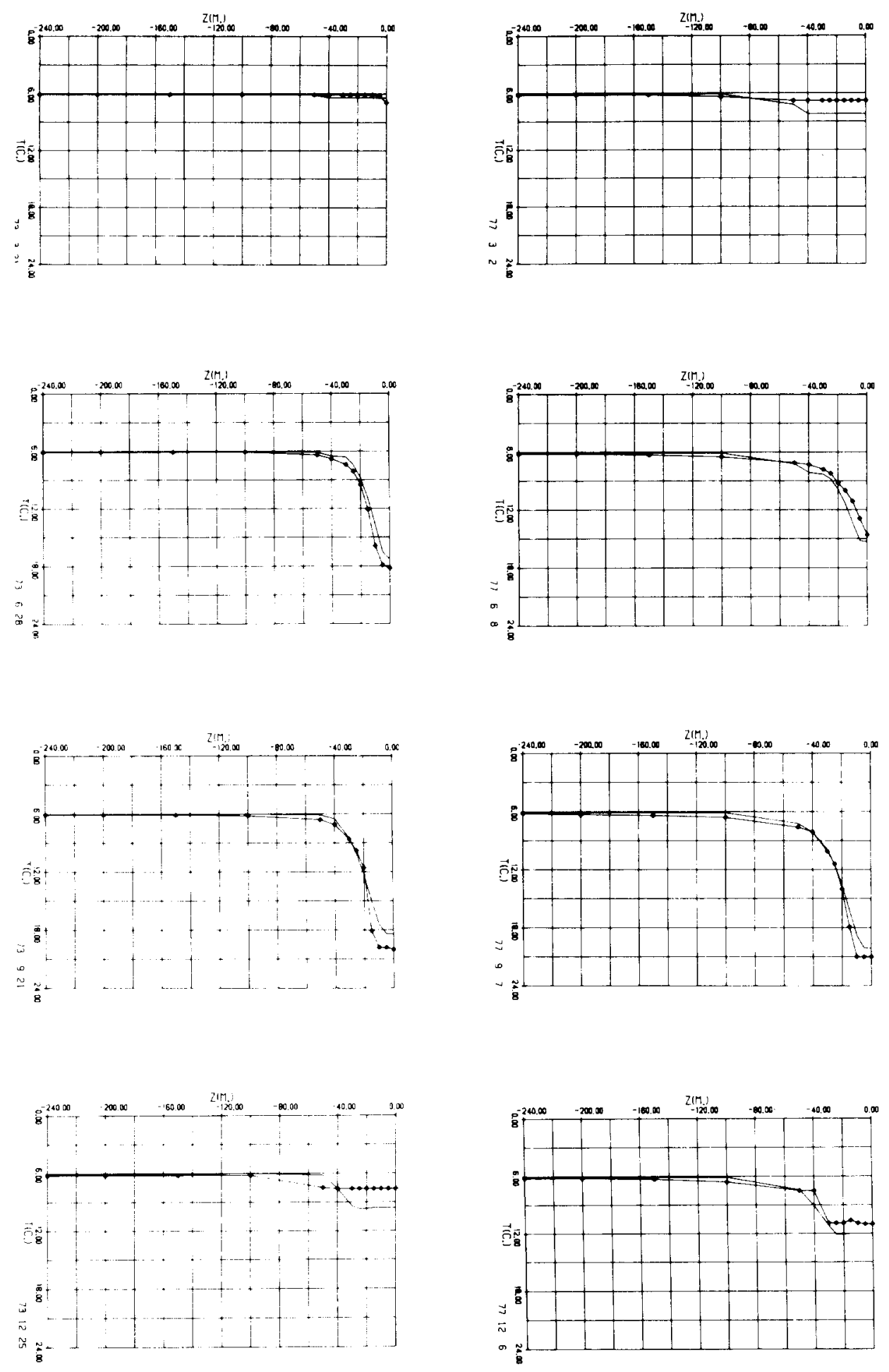

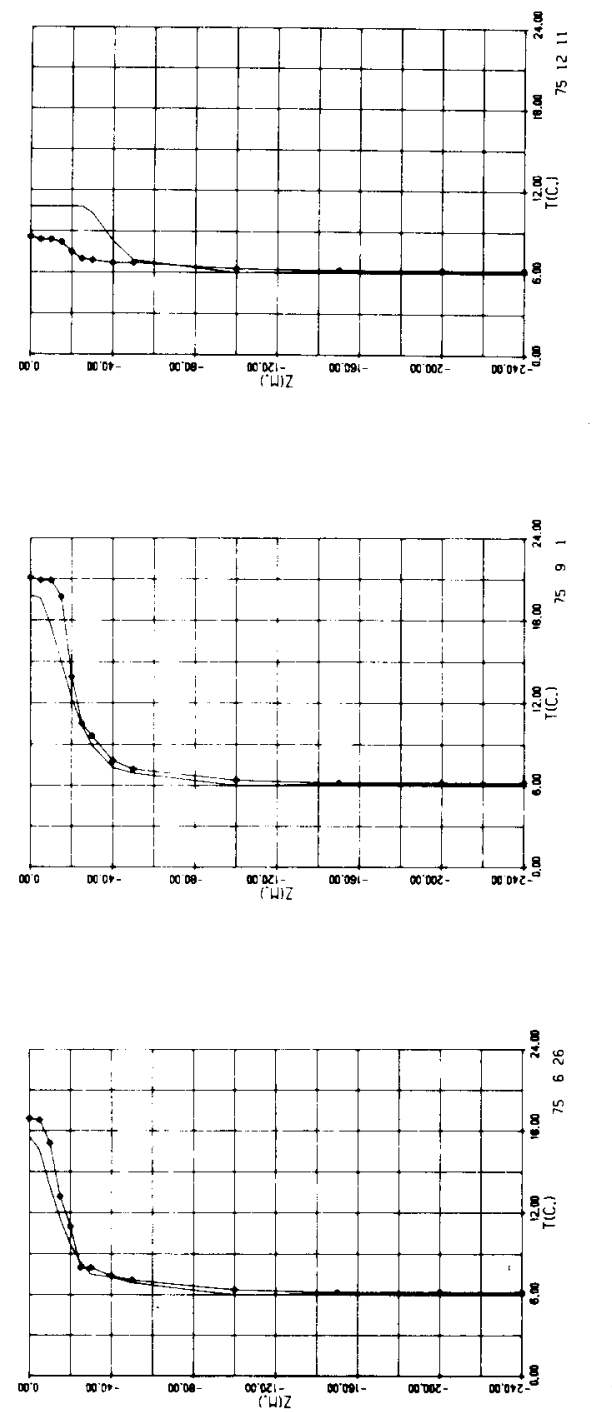

可要

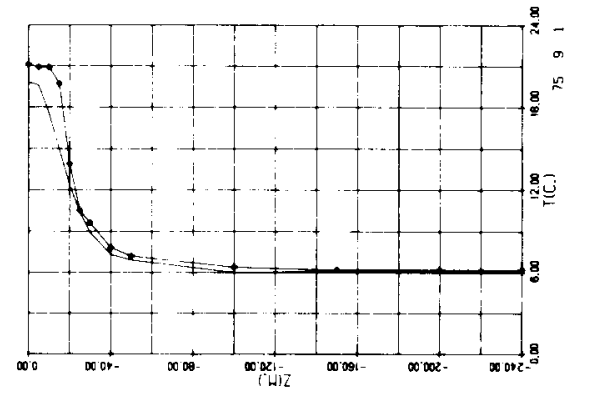

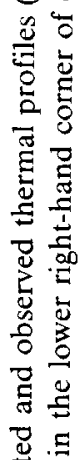

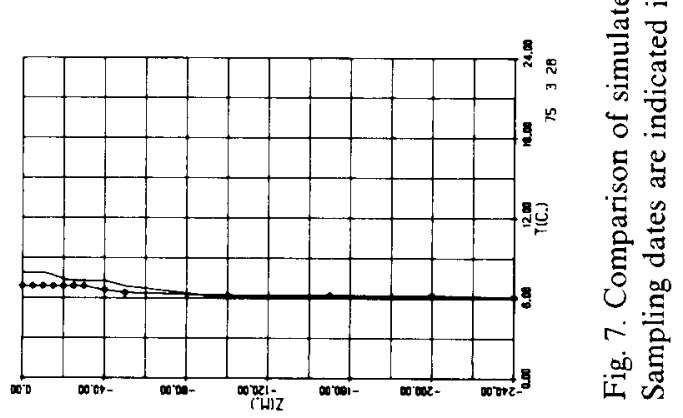




\section{ACKNOWLEDGMENTS}

Financial assistance from the Office of Fellowships and Grants. Smithsonian Institution (Grant JF-5-SMI), and from the University of Michigan and the University of Toledo are gratefully acknowledged. We also appreciate the assistance of Drs. Jordanka Serafimova-Hadžišč and Boris T. Ocevski of the Hydrobiological Institute in Ohrid in making facilities and data available.

\section{APPENDIX}

\section{Notation}

System properties

$\begin{array}{llll}a & \text { Surface albedo } & K & \begin{array}{l}\text { Conductivity of lake } \\ \text { water }\end{array} \\ m & \text { Extinction coefficient } & C & \text { Volume heat capacity }\end{array}$

Meteorological variables

$Q_{\varepsilon} \quad$ Global solar radiation

$R H \quad$ Relative humidity

$U \quad$ Wind velocity

$B \quad$ Constant in Bowen Ratio
$T_{\mathrm{a}} \quad$ Air temperature

$T_{\mathrm{skv}}$ Sky radiant temperature $\left(T_{\mathrm{a}}-22\right)$

$n \quad$ Cloud cover

Functions

$B B(T) \quad$ Black-body radiation (Sellers, 1965)

$E\left(T_{a}, R H\right)$ Vapor pressure (Magnus Equation (Pavlov, 1975))

$X(U) \quad$ Exchange coefficient (Swinbank, 1959)

$N(n) \quad$ Thermal radiation from cloudy skies (Maykut and Church. 1973)

\section{REFERENCES}

Allen, H.L. and Oceviski, B.T., 1976. Limnological studies in a large, deep, oligotropic lake (Lake Ohrid, Yugoslavia). Evaluation of nutrient availability and control of phytoplankton production through in situ radiobioassay procedures. Arch. Hydrobiol., 77: 1-21.

Carnahan. B., Luther, H.A. and Wilkes, J.O., 1969. Applied Numerical Methods. Wiley, New York, NY, 604 pp.

Hadžišce, S., 1966. Das Mixiphänomen im Ohrid-See im Laufe der Jahre 1941/42 1964/65. Verh. Int. Ver. Limnol., 16: 134-138.

Lerman, A. and Stiller, A., 1969. Vertical eddy diffusion in Lake Tiberias. Verh. Int. Ver. Limnol., 17: 323-333. 
Maykut, G.A. and Church, P.E., 1973. The radiation climate of Barrow, Alaska. J. Appl. Meterol., 12: 620-628.

Maykut, G.A. and Untersteiner, N., 1971. Some results of a time-dependent thermodynamic model of sea ice. J. Geophys. Res., 76: 1550-1575.

Outcalt, S.I., 1979. The effect of iteration frequency on a numerical model of near surface ice segregation. Eng. Geol., 13: 111-124.

Outcalt, S.I. and Allen, H.L., 1981. The thermal response of Lake Ohrid, Yugoslavia, to meteorological conditions. Arch. Hydrobiol., 91: 181-191.

Outcalt, S.I., Goodwin, C.W., Weller, G. and Brown, J., 1975. Computer simulation of the snowmelt and soil thermal regime at Barrow, Alaska. Water Resour. Res., 11: 709-715.

Pavlov, A.V., 1975. Heat transfer of the soil and atmosphere at northern and temperate latitudes of the USSR. Yatkutsk, 302 pp. (USA/CRREL draft transl. 551).

Sellers, W.D., 1965. Physical Climatology. University of Chicago Press, Chicago, IL, 272 pp.

Stanković, S., 1960. The Balkan Lake Ohrid and its living world. Monographiae Biologicae, Vol. 9. W. Junk, Den Haag, Netherlands, 357 pp.

Stanković, S. and Hadžišče, S., 1953. la Thermique du lac d'Ohrid. Recueil des Travaux, Station Hydrobiologique, Ohrid, Macedonia, Yugoslavia, 61 pp.

Swinbank, W.D., 1959. Evaporation from oceans. Sci. Rep. No. 12, AF19 (604)-2179, Dept. of Meterol., Univ. of Chicago, $15 \mathrm{pp}$.

Terzaghi, K., 1952. Permafrost. J. Boston Soc. Civ. Eng., 39: 319-368.

Walters, R.A., 1977. A numerical model of thermal stratification, primary production, and nutrient cycles in a deep temperature lake. Ph.D. Dissertation, University of Washington, Seattle, WA, 167 pp. 